\title{
Perelman, Informal Logic and the Historicity of Reason
}

\section{Christopher W. Tindale University of Windsor}

\begin{abstract}
In a posthumous paper, Perelman discusses his decision to bring his theory of argumentation together with rhetoric rather than calling it an informal logic. This is due in part because of the centrality he gives to audience, and in part because of the negative attitude that informal logicians have to rhetoric. In this paper, I explore both of these concerns by way of considering what benefits Perelman's work can have for informal logic, and what insights the work of informal logicians might bring to the project of Perelman and Olbrechts-Tyteca.
\end{abstract}

\begin{abstract}
Résumé: Dans un article posthume Perelman discute de sa décision de joindre sa théorie d'argumentation à la rhétorique plutôt qu'à la logique non formelle. Ceci est dû partiellement à l'importance qu'il accorde à l'auditoire, et partiellement à l'attitude négative des logiciens non formels à l'égard de la rhétorique. Dans cet article j'explore ses deux raisons en examinant les bénéfices que son œuvre peut apporter à la logique non formelle, et les contributions que celleci pourrait apporter au projet de Perelman et d'Olbrecht-Tyteca.
\end{abstract}

Keywords: audience, evaluation, informal logic, historicity of reason, noninteractive audience, Perelman, Reason, rhetoric.

\section{Introduction}

In a posthumous paper, Perelman makes an interesting observation: "It is on account of the importance of audience that I bring the theory of argumentation together with rhetoric rather than styling it an informal logic, as do the young logicians of today who take an interest in argumentation, but for whom the word 'rhetoric' retains its pejorative aspect" $\left(1989\right.$, p. 247). ${ }^{1}$ The identity of those "young logicians" (this would have been written in the early 1980s) must remain a mystery. What should matter to us is the choice involved along with the reasons for it. Two points emerge: that informal logic is judged not to value the importance of audience, and that logicians drawn to informal logic hold rhetoric in disdain. In considering Perelman's relationship to informal logic, I want to begin by investigating these two ideas to determine the degree to which the charges have merit, particularly over the span of the last twenty years of informal logic's development.

These are two quite different questions. It might be that in the development of informal logic an appreciation of audience has indeed emerged, while rhetoric per se is viewed negatively due to its continued association with strategies of exploitation 
in the manner of eristical tricks that bend an audience to the will of arguer in underhanded ways rather than through the force of good reasons. Whatever the case, I believe that Perelman's work shares many important themes with the projects of informal logic, such that they both have points of value to contribute to each other. Moreover, the value of what Perelman's work promises lies exactly in these two areas of concern: the positive treatment of rhetoric in argumentation, and central role of audiences with its important associated historical sense of rationality.

\section{The Reaction to Rhetoric}

The degree to which the word "rhetoric" has ever had a pejorative association for informal logicians is unclear. Perelman is less than helpful here, failing to elaborate on the remark and provide names with which he associates the attitude. While rhetoric and philosophy have long since lost the connections they held for Aristotle and those who followed him, we cannot simply infer from this that rhetoric has been viewed distrustfully simply because it has been judged irrelevant to the truthseeking goals of philosophers.

It is possible that Perelman has in mind remarks like this from Copi (1982, p.88) who speaks of rhetoric being "of course... wholly worthless in resolving a question of fact;" and the more damning statement in his Informal Logic: "In political campaigns today almost every rhetorical trick is played to make the worse seem the better cause" (Copi, 1986, p.97). But elsewhere in his standard text, Copi speaks positively about rhetoric, and the later book that seems to associate it with the tricks of eristics did not appear until after Perelman's death. More alarming is John Nolt's then-popular informal logic text which specifically identifies rhetoric as being "concerned with influencing people's beliefs without regard for truth" (1984, p.278). Again, perhaps at issue was the work of "standard" informal logicians like Johnson and Blair, with whom Perelman was familiar. ${ }^{2}$ A rhetorician giving a cursory read to the first edition of Logical Self-Defense (1977) may well be arrested by a section titled "Eliminating Rhetoric" (p.107) that offered advice on extracting the argument from the rhetoric and diluting the persuasive force of some characterizations that are built into the language. ${ }^{3}$ These selective "glimpses" may well capture the general appreciation of rhetoric (or lack thereof) in the late 1970's and early 1980's (when Perelman would have made his judgment). But it also seems reasonable to suggest that this attitude was grounded more in ignorance than ill-will. That is, philosophically-trained informal logicians were likely unaware that rhetoric could have anything other than a pejorative sense. Subsequent exposure to the works of rhetoricians and speech communication scholars, as the interests of many informal logicians has coincided with those of that community, has brought a more accurate appreciation of the wider senses 'rhetoric' can have, including the positive. Thus, later work by informal logicians has tended to reflect this greater awareness and sensitivity. ${ }^{4}$ A case in point is the Johnson and Blair text, which by the third edition (1993) asserts: "In our opinion, rhetoric as a discipline has important 
insights about argumentation which logicians need to embrace.... In our experience, logicians tend to underestimate the importance of audience and context to the comprehension and evaluation of argumentation" (pp.142-43). This corrective has the added merit of also addressing the second concern in Perelman's statement.

It is difficult, then, to see the pejorative sense of rhetoric promoted in the work of serious informal logicians. If anything, there is a tendency toward neglect rather than dismissal. Granted, the general suspicion of rhetoric in public media seems a widely shared prejudice. It is seen in the everyday rejections of positions as being largely rhetorical. More pertinently, though, it can creep into the tenor of some of the criticisms mobilized against the New Rhetoric ${ }^{5}$ (discussed below) that identifies in the focus on audience an extreme relativism which invites, if not encourages, exploitation, a goal traditionally associated with the pejorative sense. But such a license to exploit is never a view that Perelman tolerated and I will argue that no balanced reading of the New Rhetoric can seriously find support for it there.

Perelman's entire academic career is grounded in and characterized by an abiding interest in justice, and that interest saturates the work on argumentation. While not explicitly stated, it is fair to interpret the rhetorical argumentation that he develops as a counter to all moves to exploitation of audiences and as a tool that will facilitate the development of a more just society. Fairly presented, argumentation animates human freedom (1969, p.514), germinating that sphere in which reasonable choice can be exercised. And it does this because the rationality of the activity itself is predicated upon the existence of a community of minds.

Any community requires a range of commonalities of language and of interests that binds it. But entering into argumentation with others also confers value upon them, recognizes them as worth persuading and attaching importance to their agreement $\left(1969\right.$, p.16). ${ }^{6}$ Establishing communion with an audience (in the rhetorical sense) involves understanding their positions, viewing things from their perspective and sharing that perspective to some degree. Moreover, this attitude elicits "some concern for the interlocutor" and requires that the arguer "be interested in his state of mind" (p.16).

Perelman and Olbrechts-Tyteca illustrate the nature of this concern with remarks that bear on the use of the ad baculum. The use of force is contrasted with the use of reasoned argument, which appeals to the free judgment of the other person or persons, who are not seen as objects. "Recourse to argumentation assumes the establishment of a community of minds, which, while it lasts, excludes the use of violence" (p.55). One is even exhorted to employ one's own beliefs in persuasion only to the extent that the interlocutor is willing to give assent to them. Clearly, such advice tells against a pejorative sense of rhetoric where any means may be used to persuade an audience. ${ }^{7}$

Still, the menace of that pejorative sense lurks always in the shadows of the New Rhetoric, sometimes encroaching into discussions where it is identified and addressed. This is particularly evident in some of the closing sections, where the 
authors are acutely conscious of objections that may be raised to their project. Many of the strategies of argumentation and schemes they describe may be rejected as contrivances, artificial means to the end of persuasion, hiding the arguer's intentions behind a variety of devices: "Argument addressed to others and eloquence in all its forms has always been subject to disqualification and is constantly exposed to it.... It is sufficient to qualify what has been said as "rhetorical" to rob it of its effectiveness" (p.450). The charge of "device" arises like a charge of "fallacy," at least insofar as it undermines the effectiveness of the argumentation. But unlike a fallacy, a rhetorical device is indeed the vehicle of persuasiveness and needs to be retained. The more effective devices are those that go unnoticed, that appear natural. And this naturalness is achieved by a variety of means, such as matching the device to what, in the hearer's likely estimation, is appropriate for the object of the discourse (p.453). As useful as such means may be to allay the concern over devices, the most fitting strategy may be to encourage audience involvement in the argumentation itself, so that the audience shares something of what is developed. Perelman and Olbrechts-Tyteca hint that such a move is desirable when they appeal to Pascal: “...people are generally better persuaded by the reasons which they have themselves discovered than by those which have come into the mind of others" (cited in Perelman and Olbrechts-Tyteca, 1969, p.453). First-hand recognition of something is likely to be more compelling than a second-hand relating of it, because the person "sees" the point and invests in the idea. Self-persuasion, insofar as it is being explicitly encouraged here, indicates further the non-exploitative sense of rhetoric that governs the proceedings.

In light of the foregoing explanation, we can perhaps appreciate why Perelman would be so alarmed by any perceived hint of a pejorative attitude toward rhetoric in the work of like-minded logicians. It is not so much that such an attitude is misguided as that it discourages serious appreciation of rhetoric in logical contexts. It was far better to adopt the kind of perspective that animates the model of rhetorical argumentation advocated by Perelman (and Olbrechts-Tyteca). This is a model that values the audience and presents the arguer and audience as co-operating in a shared community of mutual regard.

\section{Audience}

The attention to audience in the New Rhetoric and the stress on adherence indicates a key difference from the approaches of informal logic. Argumentation, for Perelman and Olbrechts-Tyteca, involves the attempt to bring about adherence in the minds of an audience, understood as those to whom the argumentation is addressed $(1969$, p.7). Thus, the thrust of what they present is aimed at the construction of arguments, at how to put arguments together in order to win over audiences to a point of view. Informal logic, on the other hand, largely expresses an interest in the products of argumentation (the arguments) and the degree to which they can be deemed strong or cogent (Johnson \& Blair, 2000; Freeman, 2005; Finocchiaro, 
2005). ${ }^{8}$ At the same time, both sets of theorists put forward a complete model of argumentation which involves both the production or invention of arguments and criteria to assess their strength. To that end the new rhetoricians must provide some comment on evaluation and the criteria of strength to be employed; and the informal logicians must address the invention of arguments. The evaluation of the new rhetoricians, if it is going to gain wide adherence itself, must involve more than determining whether adherence has been achieved; just as the advice given by informal logicians about the construction of arguments must involve more than the avoidance of fallacies.

One theorist closely aligned with the informal logicians who has addressed the issue of audience in a critical way is Trudy Govier (1999, Ch. 11). In fact, her discussion is an implicit challenge to the work of Perelman since she judges that the kind of audience for which much argumentation is produced (particularly in the mass media) is a noninteractive audience the beliefs and intentions of which cannot be known. As she reviews the situation, informal logicians have implicitly assumed an importance for audience in a number of ways. Premise acceptability, for example, involves the evaluation of whether the premises of an argument are acceptable to someone (1999, p.185). ${ }^{9}$ This is fine for what she calls "direct evaluation," when the audience is the person being addressed directly by the argument. Even historical arguments (she uses the case of Hume's argument against miracles) can be evaluated when we take the reasonable stance that such an argument has the kind of broad relevance such that it can be treated as being directed to us. I can decide to become the audience for an argument, should I find that it addresses me. But if we look at arguments indirectly, then we are taking on a perspective other than our own where we are asking whether other people should have been persuaded by them. It is here that her concerns with the noninteractive audience come to the fore. By a noninteractive audience she means a "noninteractive, heterogeneous audience whose views are unknown and unpredictable" (p.188). Anyone who constructs arguments for the mass media, for example, or aims their arguments at nonspecialists, confronts such a noninteractive audience. Such seems to be the antithesis of the audience as it is viewed in Perelman's rhetoric. At the time of construction the arguer knows little about the audience and cannot interact with them. Not even a device like the universal audience can help us here, since the noninteractive audience shares only its indeterminateness, not its status as a standard of reasonableness.

After considering such points, Govier concludes that it is not useful to appeal to audience to resolve issues such as acceptability, and so falls back on other more standard informal logic criteria like whether premises are common knowledge, or knowable a priori, or defended elsewhere, or on reliable testimony or authority (p.199). In general, these are the criteria she uses for assessing acceptability in her own informal logic textbook (1997, and subsequent editions). Thus, it is not entirely the case that audience has been ignored in informal logic but, given the force and 
authority of Govier's critique, there seems to have been little appetite to adopt it as a central consideration in either evaluation or construction, particularly when the criteria that she has identified can be preferred.

Undoubtedly, the noninteractive audience, as Govier has presented it, is a serious challenge to those who wish to argue for the centrality of audience. I will address that below. But what might first strike us as strange is the alternative that she provides. It is by no means obvious that her criteria do avoid recourse to an audience. Granted, whether something is knowable a priori might qualify if we have no concerns about who is doing the knowing. But other criteria like "common knowledge' and 'testimony appeals' put us right back in the interactive arena. We do not know, for example, what people know in common, but we can assess what ideas and beliefs are current in certain contexts. On these terms we can assess what people in those contexts should accept. Here, we are talking about the environment of an audience that is being addressed, an environment that we share if we find ourselves addressed by the argument. In judging acceptability, we judge how well the arguer has captured that context. Likewise, whether we accept the appeal to someone's testimony or the word of an authority depends in many (perhaps most) cases on contextual features surrounding that appeal. Some claims seem strange in certain contexts, and an audience would be justified in challenging the testimony of the claimant. Much depends on what counts as normal in that context or community. Thus, it is by no means clear that Govier has provided the informal logician a raft in a sea of noninteractiveness, let alone the safety of a shore. Wherever we turn, an audience can be waiting, whether our business is construction or evaluation.

In spite of the difference of focus, Perelman and Olbrechts-Tyteca's ways of gaining adherence involve strategies of argumentation that do overlap some of the material that we would find in an informal logic text. Moreover other aspects of their account contribute useful insights to the project of informal logic generally, especially if they promise a solution to the problem of audience that still lingers after Govier's treatment.

The starting point of argumentation, for Perelman and Olbrechts-Tyteca, involves basic premises understood as types of agreement. Thus, they will speak of facts, which are types of agreement that involve no further strengthening $(1969$, p.67) and truths, which relate to systems of wider import. These primary agreements, or starting points, can suggest certain loci (or topoi) that may be employed to meet an audience where it "lives" and move its members toward a position the arguer wishes them to consider. Loci of quantity, for example, may capture generally agreed upon ideas, such as that more education is better than less. The arguer can assume this and not have to provide argumentation for it. Such presumptions can be justified in terms of what Perelman and Olbrechts-Tyteca describe as a general inertia in a society. Inertia in argumentation (like its parallel principle in physics) relates to the fund of established ideas and principles that do not need to be discussed 
anew each time because there is a weight of societal agreement in their favour (pp.105-06). ${ }^{10}$ Whether prompted by habit or a desire for coherence, we assume that what has been adopted will continue into the future unless some compelling case for change can be justified through argument (as does occur whenever we break with constraints of tradition which constitutes the body of agreements by which people live). It is, then, change, and not inertia that needs justification. But in all these instances, choices are made in relation to the intended audience. The arguer does not work in a vacuum, but against the background of a known set of beliefs and understandings that are shared with the audience. The arguments that develop may emerge as products characterized by premises and claims, but they have been crafted in situ, that is, at the point of interaction between arguer and audience. As such, the "presence" of the audience has affected the nature of the argument-has set constraints to it, conditioned its premises and even the scheme that has been adopted. If there is a parallel concept to this in informal logic, that of 'common knowledge' comes closest. In fact, on the terms just explained we can appreciate further how the preference for this idea in determining acceptability has not escaped the terrain of audience since we must always ask whose knowledge is under consideration in any judgment of 'common knowledge'. Even the arguer addressing her points in the mass media understands the broad range of attitudes and knowledge that comprise the pool of inertia at any particular time. Drawing on her own experience, Govier notes how unexpected voices in her mass audience later speak out in ways that show her arguments have been received as she could never have anticipated. But this does not undermine the value of the argumentation itself; it only speaks to its dialogical nature and the ongoing discourses that it can engender.

We see the contributions made by the audience emphasized in Perelman and Olbrechts-Tyteca's treatment of an argument type, deemed fallacious by many, and ubiquitous in informal logic textbooks, and that is the ad hominem. But the treatment this is given will not be so familiar. Perelman and Olbrechts-Tyteca have earlier made a key distinction between a particular audience and a universal audience rooted in it that represents the power of reason in that audience. ${ }^{11}$ Ad hominem arguments, with their bases in opinion, are directed at particular audiences because they will have no weight for the universal audience (p.111). The premises of such arguments "fix the framework within which the argument unfolds: it is for this reason that we link the examination of this question with agreements particular to certain argumentations" (p.111). This serves to emphasize how really audiencespecific the argumentation is at what we may think of as "ground level." Each argument is addressed to the person or persons involved, hence its ad hominem nature. By contrast, the sense in which this label has been more widely used is identified as the ad personam, the attempt to disqualify someone through a personal attack. While such strategies are not given the kind of complex treatment we now see developed in the writings of informal logic, ${ }^{12}$ their relationship to the more 
general ad hominem serves to reinforce a feature of the ' $a d$ ' arguments that is being appreciated with increasing frequency - they are context dependent and so the persuasive elements of the argument will lie not in its internal relationship between parts but externally in relation to features of the context.

This begins to show how the rhetorical not just enters in, but grounds Perelman and Olbrechts-Tyteca's approach to argumentation. Begging the Question is characterized in a similar way in a treatment that addresses what has been a problem in the logical tradition - the apparent validity of a fallacious argument. The New Rhetoric does not treat Begging the Question in a formal sense, that is, as a technique of demonstration; but as a problem of adherence. Thus, "it is not an error of logic, but of rhetoric" (p.112). It assumes that an interlocutor has already given adherence to the proposition which the arguer is trying to get that person to accept. Only within the framework of an argumentation that is rooted in a concern with audience (and not in a demonstration) can such instances of Begging the Question be appraised, because only in such contexts do we weigh what propositions an audience already accepts and which ones they might reasonably be brought to accept. It is fruitless to assess the relationship of propositions in isolation from the minds that are proposed to hold them.

Generally, other "labels" that should interest the informal logician arise in the New Rhetoric in relation to similar concerns. Perelman and Olbrechts-Tyteca approach the construction of argumentation in terms of techniques, some of which, like the Argument of Waste (p.279), ${ }^{13}$ are based on the structure of reality and others of which, like the Argument from Analogy (p.372), ${ }^{14}$ establish the structure of reality. In each case, the technique is to be employed in relation to the intended audience and appropriate strategies for gaining the adherence of that audience in a reasonable way. In a similar way, they had previously presented the techniques that they term quasi-logical arguments. These arguments acquire their persuasiveness from their resemblance to formal patterns of argument. So 'incompatibility' resembles 'contradiction' (pp.195-97) and ridicule borrows its persuasiveness from the reductio (p.205). But in each case the appeal is to the underlying circumstances rather than to a formal system. Propositions become incompatible, for example, "as the result of a certain determination of notions with respect to particular circumstances" (p.201); and the ridiculous arises in contrast to opinions that are accepted (p.206). While we cannot suggest a parallel between quasi-logical arguments and informal argument patterns, since the latter do not derive their force from any close relation with formal logic, they do share a common agenda of dealing with reasoning outside of formal systems, of being in their respective ways logics of argumentation (where this is set in contrast with demonstration). Among the large variety of techniques advanced by Perelman and Olbrechts-Tyteca, whether quasi-logical, based on reality, or establishing the structure of reality, the choices governing the construction of the content and the techniques to be employed arise always in relation to the audience whose adherence is at issue. ${ }^{15}$ 


\section{Evaluation}

Where there is more room for overlap between Perelman's approach and informal logic is in the common interest in evaluation. While the majority of the New Rhetoric seems aimed at construction, the model cannot be presented as a complete model of argumentation without some sense of how argumentation will be evaluated. Of course, the pat response to this is to echo Perelman and Olbrechts-Tyteca's own remarks throughout the opening sections of the book: Argumentation aims at the adherence of an audience and so the obvious measure of that success is seeing that such adherence ensues. Thus we see critical reactions to the model restricting its notion of soundness to this condition. A common reaction is the following:

Perelman and Olbrechts-Tyteca offer a rhetorical concept of rationality in which soundness of argumentation is equated with the degree to which argumentation is well suited to those for whom it is intended. This means that the soundness of argument is, according to this criterion, always related to an audience. (van Eemeren, et. al., 1996)

This assumption that the New Rhetoric reduces soundness to effectiveness is partly encouraged by the way Perelman and Olbrechts-Tyteca present their ideas. The way they reconsider, for example, the distinction between persuading and convincing, that has traditionally divided rhetoricians and philosophers, can create confusion. They talk at length about the way those concerned with action value persuasion, while those concerned with the rational character of adherence value convincing (1969, p.27). But as they also explain, this distinction itself is misconceived. While a syllogism may induce conviction but not persuasion, that is only because it is being considered in isolation from its context, as a product. It is for this reason that they explicitly refuse to adopt a sharp division between the two. They are interested in "the difference between conviction and persuasion as it is experienced by the hearer," (p.29) and judge that this will always be imprecise. The hearer, while persuaded, "imagines transferred to other audiences" (p.29) the argument presented, and so considers it both at the level of the personal and at the level of the general. Hence, conviction reinforces persuasion and cannot be clearly distinguished from it. This begins to suggest ways around the charge that effectiveness is all that is at issue, but it does not tell the whole story, nor does it disperse the spectre of relativism that is often associated with it (van Eemeren and Grootendorst, 1995-an extreme relativism, really, that sees the criteria of reasonableness not relative to communities but to individual arguers. ${ }^{16}$

We cannot ignore the emphasis on adherence in the early parts of the New Rhetoric that give fuel to this reading. But nor should we ignore what might be viewed as the climax of the book with its turn to a discussion of when arguments are strong, and when weak. In terms of the general tone of the critique, we might expect the answer there to be something along the lines of: when we see an audience act in a way that indicates adherence to the claim, then the argument is strong because successful; and when we see no adherence take root, the argument is 
weak. Perelman and Olbrechts-Tyteca do say some things that gesture in this direction. The strength of arguments will be connected to a hearer's adherence to the premises (p.461). But this is adherence at the starting point of an argument, not its terminus in action. The strength of an argument lies partly in the difficulty that there is in refuting it. Thus, while the strength of arguments will vary with the audience, this is in relation to the types of arguments that are chosen for different audiences. They note, for example, that Aristotle recommended argument by example for deliberative oratory and Whately advised arguments from cause to effect when addressing certain minds. The intent here is to focus on the arguments used and criteria of strength associated with them and in particular their refutation. They then raise what must be the crucial question for informal logicians reading the New Rhetoric: "Is a strong argument an effective argument which gains the adherence of the audience, or is it a valid argument, which ought to gain it?" (p.463). Like many distinctions Perelman and Olbrechts-Tyteca evoke, this one cannot be absolute. What would count as the normal (descriptive) and the norm (prescriptive) can only be defined through "an audience whose reactions provide the measure of normality and whose adherence is the foundation of standards of value" (p.463). This is to ask whence our standards of reasonableness arise, in relation to which audience? To address these kinds of questions and respond to their own regarding strength, Perelman and Olbrechts-Tyteca invoke an earlier discussion of the rule of justice.

Success is one thing, and certainly the rhetorical arguer pursues this. But she also wants success on rational grounds, and to that extent her argument must meet a more exacting condition that will allow it to be tested. The rule of justice is first introduced back in the section on quasi-logical arguments. There, the rule of justice requires "giving identical treatment to beings or situations of the same kind. The reasonableness of this rule and the power that it is recognized as having derive from the principle of inertia, from which originates in particular the importance that is given to precedent" (pp.218-19). As we saw above, established ideas and principles do not need to be discussed anew each time because there is an inertial force of societal agreement in their favour. For Perelman in particular this idea underlies the legal validity of precedence in law. In these terms, the rule of justice allows us to pass from earlier cases to future cases (p.219).

At the close of the book (what Crosswhite calls its "center of gravity" [2000, p.7]), this rule is brought in to address the discussion of validity. After all, what provides the criterion of validity $?^{17}$ Usually, it is some theory of knowledge involving techniques that have been effective in various fields of learning and that can be transferred to others. This has given rise to the clash between the methodologies of different fields and the quest for the unity of science grounded in the criterion of self-evidence. But when the self-evident is the criterion of validity it discredits all argumentation which may be effective but does not provide "real" proof. This aside (since Perelman and Olbrechts-Tyteca's entire project has resisted this kind 
of thinking), there can be no doubt that a distinction is made between weak and strong arguments, and so they write:

Our hypothesis is that this strength is appraised by application of the rule of justice: that which was capable of convincing in a specific situation will appear to be convincing in a similar or analogous situation. The comparison of situations will be the subject of constant study and refinement in each particular discipline. (p.464)

We might reasonably ask how this will work, how would the norms of reasonableness that guarantee validity be recognized through the rule of justice? A fitting answer to this is suggested through their treatment of the Red Herring, which they understand in terms familiar to informal logicians as a problem of shifting a discussion to another subject that is considered irrelevant (p.484). If there was agreement as to the irrelevance of diversions, this device would characterize weak arguments:

But there seldom is. The charge of diversion and the charge of fallacy are alike in that they both assume that the introduction of the irrelevant or fallacious argument was deliberate. Now the charge can be sustained only in cases where there is a substantial departure from what is usual. It is indeed theoretically possible to deny that such parts of a discourse as the exordium and peroration have any argumentative value, and to treat them as diversions. It is the application of the rule of justice that enables one to arrive at an opinion in this matter. (p.485)

The answer suggested here is that we look to similar, established cases to determine what should count as relevant in this case. If there is a precedent set or a presumption in favour of treating the exordium and peroration as parts of the argument, then they are not diversions. The conditions of the Red Herring brought to bear on the case and framing the matter raise exactly this kind of question and serve as an example of reasonable criteria that transcend particular cases and determine validity by means of what is generally accepted.

More particularly, there are implications here for the authority of the Red Herring itself as such a set of conditions. ${ }^{18}$ The Red Herring is a pattern or regularized typology of argument. But where do its conditions come from? To say that we can detect them already in Aristotle's remarks on diversions (Topics, 111b31-112a11) is not an answer. From where does Aristotle get his understanding for dealing with it? After all, some fallacies have fallen by the wayside over the course of the tradition, and for others we allow both reasonable and unreasonable versions of the arguments.

The rule of justice points to the pattern itself as having been drawn from cases that define it. It is part of a community's grounded understanding of what count as conditions of reasonableness. This commonality challenges the extreme relativism identified above. Arguers belong to communities of reasoners, communities that they have in common with their audiences. In this sense, they share the common patterns of what is reasonable. Simply put, the rule of justice provides a constraint 
on mere acceptance. Audiences are not free to accept whatever they would like. They operate in a field of reasoning that provides established judgments and the patterns on which they have been judged reasonable. Whatever we accept has to fit with what has been accepted in other, similar instances. This is what gives coherence to our judgments and a sense of our belonging to a community of reasoners. We can challenge the standards we inherit, argue that they do not transfer to our case, argue that they are misapplied, but we cannot ignore them. Arguers appreciate this; such standards are part of the cognitive environment of the audiences they interact with, at a level at which we all interact.

Another of the later sections of the New Rhetoric explores the concept of dissociation (one, along with association, that had been introduced earlier). The strategy of dissociation involves taking an established concept and dividing it along particular lines, with one of the separated elements promoted as having a value over its more traditional counterpart. ${ }^{19}$ An incompatibility in the way a concept appears gives rise to the break among the original unity of elements within the single concept. A contemporary example is suggested in the way 'cloning' is separated into therapeutic and reproductive varieties, with value attached to the first. Perelman and Olbrechts-Tyteca suggest that this strategy is characteristic of how new concepts emerge in the history of philosophy, and they provide a wealth of examples to illustrate their proposal (1969, pp.415-38). Once this strategy has been introduced and has been understood, the reader is able to look back at the terrain of the New Rhetoric and the wider expanse of Perelman's work generally and appreciate it as a series of dissociations, most clearly of 'reason' itself. Elsewhere (1963, p.158), Perelman contrasts historic reason (with the rule of justice as its constituent principle) with an eternal reason (principles of identity and non-contradiction). I think we can assign these places within the respective columns of argumentation and demonstration. What makes one reason "historic" rather than eternal is that it exhibits what we might call an "historicity." It allows us to conceive of reason not as ahistorical and fixed, but something that arises in history and moves and changes through history, like the pattern 'Red Herring'. Crosswhite captures something of what is at stake here when he writes: "The measure of reasoning is not some timeless logical standard located in the essential nature of constantly present things" (1996, p.36). The measure of reasoning is always an audience in history, drawing off of audiences in contiguous times and locations, but able to change and modify its standards as experience and the argumentation presented to it warrants. "The historicity of reason," writes Perelman, "is always closely connected with it becoming part of a tradition" (1963, p.157). The power of inertia is a strong force stabilizing our reasoning and resisting the spectre of extreme relativism. But reason remains historical, albeit an almost-tradition, open to the justifications for changing standards. A graphic illustration of this, I would suggest, are the emerging standards of informal logic, like those for argument evaluation and the criteria for identifying and assessing fallacies. 
The fitting comparator to reason's historicity is that of science. Since at least Kuhn (1962) we have been apprised of the ways in which science, like reason, is historical, reflected in the collective achievement of the group. Kuhn recognizes the group (admittedly, the "uniquely competent professional group") as the exclusive arbiter of achievement (1962, p.168). But, importantly, the standard lies solely within this community, never outside it. The inertia exhibited by normal science and the shifts of change in extraordinary science both exhibit progress. ${ }^{20}$ The parallel is compelling.

When we construct arguments aimed at a generalized audience, and when we evaluate the same, it seems implausible that we confront the vague and unresponsive anonymity that Govier imagines as her noninteractive audience. There is always something there at which we direct our ideas, even if it is only at first an expanded mirror of ourselves. In the ongoing interaction, that audience takes shape and the dialogue becomes more meaningful. But when we assess the reasonableness of that audience's actual and expected responses, we assess them according to standards that are alive in that audience and shared between arguer and audience. We may fall back on 'audience-independent' criteria like common knowledge, testimony, etc. But those measures of what is reasonable only work because they are shared by the audiences concerned. Because, Perelman is suggesting, those criteria do not drop fully made into the logician's tool box. They work because they are shared and have been passed through history from audience to audience.

\section{Conclusion}

"Every systematic treatment of argumentation has two branches, one concerned with invention of arguments and the other with judgement of their validity." (Cicero, Topics II6)

On balance, there is much to look for in any blending of the two approaches. After all, I have yet to ask what Perelman meant by informal logic in the remark taken from his late work. Given the general distinction he and Olbrechts-Tyteca drew between demonstration with its self-evident truths compelling assent from all rational minds and eschewing the need for argumentation, and argumentation itself, that sphere which eludes certainty and concerns the credible, plausible and probable, it seems uncontroversial that Perelman would take informal logic to be the logic of such argumentation. And while Perelman's project, as set out in the New Rhetoric, does not share all the goals of informal logic, as theories of argument, they cannot help but have interests in common matters and ideals. This comes to the fore in the question of evaluation, on which a fruitful exchange between the two approaches to argumentation might ensue. In particular, the clarity of schemes and more detailed criteria of evaluation that have emerged in informal logic would help tighten the looser ideas of the New Rhetoric; while the latter's greater sensitivity to the importance of audience promises to enrich the work of informal logic. ${ }^{21}$ 


\section{Notes}

${ }^{1}$ Perelman and Olbrechts-Tyteca offer the same explanation for choosing to call their approach rhetorical rather than dialectical (1969, p.5; p.54).

${ }^{2} \mathrm{He}$ had been invited to join the editorial board of Informal Logic, but declined because of what he took to be its purely pedagogical focus, perhaps basing his judgment on the earlier Informal Logic Newsletter.

${ }^{3}$ While in the Proceedings of the First International Symposium on Informal Logic, Johnson and Blair identify The New Rhetoric as one of only three monographs of significance to informal logic, still the program set out there distinguishes informal logic and rhetoric as separate disciplines whose relationship is unclear $(1980$, p.26).

${ }^{4}$ See, for example, the article by Groarke (2007) in the Stanford Encyclopedia of Philosophy http:/ /plato.stanford.edu/entries/logic-informal/\#Rhe.

${ }^{5}$ This is the phrase I will use to refer to the perspective or account we associate with Perelman. When explicit reference is made to the central work he co-authored with Olbrechts-Tyteca, then the title will be italicized.

${ }^{6}$ Nor does all argumentation aimed at adherence involve persuasion. Some techniques, like illustration (1969, p.357), are designed to strengthen an adherence that is already present.

${ }^{7}$ Nor should the construction of a universal audience (for each particular one) be seen to counter this concern for real interlocutors. In a discussion that includes consideration of Perelman and Olbrechts-Tyteca's universal audience, Ricoeur (2000, p.118) observes that the universality at stake would not seem to be the inner monologue often associated with Kant's universal, but the dialogical connection to an audience grounded in others.

${ }^{8}$ To take observations from this admittedly selective group: Johnson \& Blair (2000) suggest that leading practitioners of informal logic, like Trudy Govier, Douglas Walton, and themselves see its mandate as "the study of norms of argument" and construe a definition of informal logic that fits the practices of all those they have identified: "Informal logic designates that branch of logic whose task is to develop non-formal standards, criteria, procedures for the analysis, interpretation, evaluation, critique and construction of argumentation in everyday discourse" (2000, p.94). Freeman identifies the interests of informal logic with the "issues of argument evaluation," specifically whether the premises are justified and the conclusion is then justified by the premises (2005, p.x). Finally, Finocchiaro provides the most comprehensive definition by presenting informal logic as the theory of reasoning (2005, p.22) and later the theory of argument (p.93). By this in turn he means "the attempt to formulate, to test, to clarify, and to systematize concepts and principles for the interpretation, the evaluation, and the sound practice of reasoning" (p.22). While construction is not absent from the sights of informal logicians, the concern has been first and foremost to develop standards of evaluation. But as exceptions to this we should note Vorobej (2006, pp.4-5), Pinto (2001, p.119) and Govier (1999, p.185).

${ }^{9}$ Moreover, the judgment that premises are relevant to the conclusion they support assumes that connection can be recognized, and whether a premise-set meets a sufficiency requirement may depend on the context in which it is being assessed.

${ }^{10}$ An excellent discussion of inertia in the New Rhetoric is provided by James Crosswhite (2000).

${ }^{11}$ I have tackled the notion of the universal audience and tried to develop Perelman and OlbrechtsTyteca's account in several places: see Tindale, 1999, chapters $3 \& 4 ; 2004$, chapter 6 , and forthcoming.

${ }^{12}$ See Walton (1988).

${ }^{13}$ Consider the strategy of argument popularized by George W. Bush:

'We have invested enormous resources of money and lives in the reconstruction of Iraq. To withdraw now would be a tremendous waste of those commitments. Thus we should stay the course and finish the job.' 
${ }^{14}$ Their analysis involves a relationship of structures ( $\mathrm{A}$ is to $\mathrm{B}$ as $\mathrm{C}$ is to $\mathrm{D}$ ) belonging to different spheres, along the lines of what Aristotle provides in De Anima: The soul is to the body [A to B] as sight is to the eye [C to D]. No one expects sight to survive the death of the eye. And so (A is to $\mathrm{B}$ as $\mathrm{C}$ is to $\mathrm{D})$-no one expects the soul to survive the death of the body.

${ }^{15}$ As a rhetorical model of argumentation, Perelman's promotes the Aristotelian triad of logos, ethos and pathos. In the limited space available here, and with respect to its particular relevance, I have focused on the logos. But the New Rhetoric also gives ample attention to questions of ethos, particularly as this concerns the prestige of the arguer and question of the act-person relationship (1969, p.303). It is a more contentious issue as to whether the expected attention to pathos is present. Gross and Dearin (2003) criticize this as a serious omission. But we might see some questions of pathos raised indirectly in, for example, the technique of appealing to symbols. The image of a malnourished HIV sufferer in Africa is a pathotic appeal because of what that image represents as a symbol.

${ }^{16}$ Van Eemeren and Grootendorst charge that soundness will vary from case to case depending on the criteria employed by the audience: "This means that the standard of reasonableness is extremely relative" (1995, p.124). On this reading, there can be as many definitions of reasonableness as audiences and, if attention is shifted to the universal audience constructed by arguers, as many definitions of reasonableness as there are arguers.

${ }^{17}$ Nothing they say here suggests they mean the validity associated with formal demonstrations. What they have in mind seems closer the kind of inductive validity advocated by C.L. Hamblin (1970, p.225; p.245ff.).

${ }^{18}$ And here, of course, informal logicians provide a welcome advance on such thinking with several considered treatments of criteria for this and other argument types.

${ }^{19}$ The concept of dissociation has been extensively explored and developed in the work of van Rees (2002; 2005).

${ }^{20}$ As Kuhn also points out (pp.171-72), marking the absence of "truth" from his account, the fact that we progress from a primitive point does not mean we move toward a goal. Likewise, no teleological account of reason is assumed here. I am grateful to James Crosswhite for drawing the relevance of Kuhn's history to my attention.

${ }^{21}$ An earlier version of this paper was discussed by the members of the Centre for Research in Reasoning, Argumentation and Rhetoric (CRRAR) at the University of Windsor. I am grateful to all those involved for their discussion and particularly to Ralph Johnson and David Godden for their detailed comments. I am also grateful for the comments of James Crosswhite and a further, anonymous, referee.

\section{References}

Cicero. (1949). Topics. H.M. Hubbell (Trans.). Cambridge, Mass.: Harvard University Press.

Copi, I.M. (1982). Introduction to Logic (6 $6^{\text {th }}$ ed.). New York: Macmillan Publishing Co. Copi, I.M. (1986). Informal Logic. New York: Macmillan Publishing Co.

Crosswhite, J. (2000). "Nature and Reason: Inertia and Argumentation," in Argumentation at the Century's Turn. C.W. Tindale et. al., (Eds.) Ontario: OSSA, 13pp.

Crosswhite, J. (1996). The Rhetoric of Reason: Writing and the Attractions of Argument. Madison, WI: The University of Wisconsin Press. 
Eemeren, F.H. van and R. Grootendorst. (1995). "Perelman and the Fallacies," Philosophy and Rhetoric. 28: 122-33.

Eemeren, F.H. van, et. al. (1996). Fundamentals of Argumentation Theory. Mahwah, NJ: Lawrence Erlbaum.

Finocchiaro, M. (2005). Arguments about Arguments. Cambridge: Cambridge University Press.

Freeman, J. (2005). Acceptable Premises: An Epistemic Approach to an Informal Logic Problem. Cambridge: Cambridge University Press.

Govier, T. (1999). The Philosophy of Argument. Newport News, Virginia: Vale Press.

Govier, T. (1997). A Practical Study of Argument. 4e. Belmont:Wadsworth.

Groarke, L. (2007). "Informal Logic," Stanford Encyclopedia of Philosophy. [http:// plato.stanford.edu/entries/logic-informal/\#Rhe].

Gross, A.G \& R.D. Dearin. (2003). Chaim Perelman. Albany. NY: State University of New York Press.

Hambin, C.L. (1970). Fallacies. London: Methuen.

Johnson, R.H. and J.A. Blair. (2000). "Informal Logic: An Overview," Informal Logic. 20: 93-107.

Johnson, R.H. and J. A. Blair. (1980). “The Recent Development of Informal Logic,” in Informal Logic: The First International Symposium, Johnson \& Blair (Eds.) Pt. Reyes, CA: Edgepress: 3-28.

Johnson, R.H. and J.A. Blair. (1977/1993). Logical Self-Defense. ( $1^{\text {st }}$ e/3 $3^{\text {rd }}$ e) Toronto: McGraw-Hill Ryerson.

Perelman, Ch. (1963). The Idea of Justice and the Problem of Argument. London: Routledge \& Kegan Paul.

Perelman, Ch. (1989). "The New Rhetoric and the Rhetoricians: Remembrances and Comments," The New Rhetoric of Chaim Perelman: Statement and Response. Ed. R.D. Dearin. New York: University Press of America.

Perelman, Ch. and L. Olbrechts-Tyteca. (1969). The New Rhetoric: A Treatise on Argumentation. Trans. J. Wilkinson \& P. Weaver. Notre Dame: University of Notre Dame Press.

Nolt, J.E. (1984). Informal Logic: Possible Worlds and Imagination. New York: McGrawHill Book Co.

Pinto, R.C. (2001). Argument, Inference and Dialectic. Dordrecht: Kluwer Academic Publishers.

Rees, M.A. van. (2002).. "Argumentative functions of dissociation in every-day discussions." In H.V. Hansen et. al. (Eds) Argumentation and its Applications. Windsor: OSSA, 14pp.

Rees, M.A. van. (2005). “Indications of Dissociation.” In F.H. van Eemeren \& P. Houtlosser (Eds.) Argumentation in Practice. Amsterdam: John Benjamins Publishing Co., pp.5367.

Ricoeur, P. (2000). The Just. Chicago: University of Chicago Press.

Tindale, C.W. (Forthcoming). "Constrained Maneuvering: Rhetoric as a Rational Enterprise," Argumentation. 
Tindale, C.W. (2004). Rhetorical Argumentation: Principles of Theory and Practice. Thousand Oaks, CA: Sage.

Tindale, C.W. (1999). Acts of Arguing. Albany, NY: State University of New York Press. Vorobej, M. (2006) A Theory of Argument. Cambridge: Cambridge University Press.

Walton, D.N. (1988). Ad Hominem Arguments. Tuscaloosa, AL: University of Alabama Press.

Christopher W. Tindale Centre for Research in Reasoning, Argumentation and Rhetoric Department of Philosophy University of Windsor Windsor, $O N, N 9 B 3 P 4$ ctindale@uwindsor.ca 